\title{
Science students' conceptions of factors that will differentiate them in the graduate employment market
}

\author{
Trina Jorre de St Jorre ${ }^{1}$, Joanne Elliott ${ }^{2}$, Elizabeth D. Johnson ${ }^{3}$, Stewart Bisset ${ }^{4}$ \\ trina.j@deakin.edu.au; joanne.elliott@deakin.edu.au; liz.johnson@deakin.edu.au; \\ stewart.bisset@deakin.edu.au \\ Corresponding author: Trina Jorre de St Jorre \\ ${ }^{1}$ Senior Lecturer, Student Achievement, Deakin Learning Futures, Deakin University, Geelong, \\ Australia. ORCID: 0000-0001-7848-0305 \\ 2Lecturer, Digital Innovation, Deakin Learning Futures, Deakin University, Geelong, Australia. ORCID: \\ 0000-0003-4923-0432 \\ ${ }^{3}$ Deputy Vice-Chancellor Education, Deakin University, Geelong, Australia. ORCID: 0000-0002-7929- \\ 5272 \\ ${ }^{4}$ Research Assistant, Deakin Learning Futures, Deakin University, Geelong, Australia.
}

\begin{abstract}
To gain employment and a fulfilling career, students need to understand the skills and knowledge that are important and how to articulate and evidence their employability. This paper reports on research investigating science students' priorities related to immediate employment versus long-term employability and the factors that students perceive as important to these. Interviews with 138 science students from four Australian universities revealed that they were most focused on immediate employment. Students were keen to participate in opportunities to 'value add' to their degree, especially those that might help them to gain relevant work experience and professional networks. However, students' understanding of the relative importance of experiences and skills that would enhance their employability was variable, as was their understanding of the career pathways that they might pursue. The data analysis highlights the importance of explicitly designing curriculum to help students understand the career opportunities available; the skills and abilities needed for diverse careers; and the experiences through which they might develop and evidence these. Furthermore, to engage students, we need to help them to address their greatest and most immediate concerns about gaining employment at graduation, while also setting them up for successful and fulfilling careers.
\end{abstract}

Keywords: employability, work-integrated learning, student voice, student engagement, career development, curriculum

\section{Introduction}

Globalisation, rise of the share economy and rapid advances in technology (from robotics and artificial intelligence to nano- and bio-technology, amongst others) have changed patterns of consumption, production and employment across the world (World Economic Forum, 2016). As a result, the world of work and jobs 'on offer' are rapidly changing: many of the occupations or specialisations that are currently in demand did not exist ten or even five years ago, while others have become obsolete or are threatened by redundancy (World Economic Forum, 2016). The concept of a 'career' has also evolved and individuals now more frequently move between disciplines or industries, either out of necessity, to accommodate new interests, or to gain better opportunities (World Economic Forum, 2016). Meanwhile the skills required for 
existing jobs are changing and the skills gap has widened (AlphaBeta, 2016; World Economic Forum, 2016).

Employers are increasingly looking for graduates with evidence of transferable skills that are important in any workplace (The Australian Industry Group, 2018). An investigation of more than 6000 websites and 4.2 million job advertisements over three years (2012-2015) showed that transferable or 'enterprise' skills are increasingly demanded in early-career job advertisements, and are now more frequently required than discipline-specific skills (defined as those associated with a specific task, role or industry: AlphaBeta, 2016). Furthermore, jobs that demand those skills, especially highly sought-after skills such as advanced communication skills and digital literacy, are associated with a higher rate of pay than those that do not stipulate that requirement (AlphaBeta, 2016). Simultaneously in Australia, participation in higher education has been rising, making completion of a university degree less distinctive in the labour market.

Graduates are faced with two challenges: they need to recognise and adapt to rapidly changing career opportunities, and distinguish themselves from their peers to secure those opportunities (Oliver \& Jorre de St Jorre, 2018; Tomlinson, 2008). Institutions responsible for education and training need to assist students by emphasising the development of transferable skills and knowledge that are relevant to graduates creating and finding work (Oliver \& Jorre de St Jorre, 2018). These challenges are particularly acute for generalist degrees, like science, that are associated with diverse career pathways (Palmer, Campbell, Johnson, \& West, 2017).

One way in which universities and discipline groups are ensuring that curriculum reflects learning that will be valuable in the workplace, is through seeking input from industry and professional groups and including more opportunities for 'work-integrated learning' (ACEN, 2015; Johnson \& Rice, 2016; Sachs \& Rowe, 2016). 'Work-integrated learning' is a term commonly used to describe a broad range of activities that help students to integrate theory with the practice of work, including experiences situated in a workplace (such as internships, placements, field trips or job shadowing) as well as other experiences that happen on campus but are authentic to the workplace (such as case studies, simulations or other workplace tasks) (Orrell, 2011; Patrick et al., 2009).

Work-integrated learning (WIL) has received sector and government recognition, as a way of helping students to orientate to the workplace and develop skills and attributes that are important to obtaining jobs, adapting to changing job roles, and performing well in the workplace (Atkinson, Misko, \& Stanwick, 2015; Jackson, 2015; Patrick et al., 2009). Although the term (WIL) itself is not commonly used amongst employers, industry are increasingly linking with universities to provide work placements, talks, tours and opportunities for job shadowing (The Australian Industry Group, 2018). Work experience is a selection criteria often used in the recruitment of graduates, and placements are a common graduate recruitment pathway in some industries (Australian Association of Graduate Employers, 2018). It is therefore not surprising that graduates that participate in WIL, such as placements, tend to gain employment more quickly after graduation (Ferns, Campbell, \& Zegwaard, 2014).

However, in addition to providing students with WIL opportunities in the curriculum, it is also important that universities help students to understand how they leverage those opportunities to build personal capability and manage their careers. The value gained through WIL and subsequent experiences is dependent on student engagement and action. This raises the question, do students have realistic beliefs about the long-term goal of ongoing employability as well as the immediate problem of employment? And are those perceptions aligned with those of industry and educators?

Graduate employability has been defined and conceptualised in numerous ways (Curtis \& McKenzie, 2001; Oliver, 2015; Tomlinson, 2012; Yorke, 2006). There is general agreement that it derives from complex learning and requires a wide range of transferable skills beyond 
the 'core' knowledge and skills required for specific disciplines (Yorke, 2006). It is distinct from measures of graduate employment which are affected by a range of social, personal and economic factors (Tymon, 2013). In this paper, the popular definition of graduate employability first articulated by Mantz Yorke (2006) and re-defined by Oliver (2015) is adopted:

Employability means that students and graduates can discern, acquire, adapt and continually enhance the skills, understandings and personal attributes that make them more likely to find and create meaningful paid and unpaid work that benefits themselves, the workforce, the community and the economy (p.59).

In comparison to those investigating the views of other stakeholders (e.g. higher education personnel or employers), student conceptions of employability have only been explored by a small number of studies. Most of these have focussed on the skills or attributes that students perceive as important to employability or where students perceive these to be developed in their degree (Hill, Overton, Thompson, Kitson, \& Coppo, 2018; Jackson, 2014; 2015; Jorre de St Jorre \& Oliver, 2018; Kavanagh \& Drennan, 2008; Sakar, Overton, Thompson, \& Rayner, 2016; Tymon, 2013). Other studies have investigated student perceptions of the value of a degree to their employability, and have shown that students perceive higher education as necessary for gaining access to a wider range of jobs, higher pay and a more enjoyable career. However, students also perceive the value of a degree as declining and understand that extracurricular experiences and development of broader skills are integral to competing in the labour market at graduation (Tomlinson, 2008; Tymon, 2013), and further into the future (Glover, Sue, \& Youngman, 2002).

Few studies have specifically investigated the experiences that students perceive as important. Those that have, tend to focus on students' experience of university curriculum and services, rather than on students' broader understanding of the experiences, behaviours or other factors that might influence their employment or career prospects. However, we found three studies that provide some insight into student perceptions of actions that improve employability and employment outcomes. It is noteworthy that all three of these studies found that direct experience of workplaces through placement was the opportunity most valued by students.

The first study investigated students' understanding of employability and related skills, their perceptions of its importance and university support for its development (Tymon, 2013). Focus groups and a questionnaire were used to collect the views of over 400 undergraduates in first, second and third-year business degrees (business studies/administration, human resources and marketing) at a single university in the UK. All year groups perceived placements as the most valuable opportunity to develop employability at university. Students also highly valued careers support (e.g. support for resume writing and job or placement seeking) and mentioned embedded activities, such as presentations, group work and meeting deadlines, designed to develop skills/attributes such as communications, confidence, team-work and selfmanagement (p. 851). Few students mentioned student-driven activities, such as societies, volunteering and other extra-curricular opportunities, and Tymon suggests this reflects a lower perception of value. However, an alternative interpretation is that it might reflect the framing of questions. Students were specifically asked about support expected from or provided by their university, and may not have perceived these 'student-driven' activities as being supported or provided by their institution. Although some students also perceived grades to be important, less than 40 percent of students connected qualifications or grades to employability.

In a second study, a survey was used to investigate factors that contribute to students' confidence in their employability. Students were asked to report their confidence related to employability and other potentially related variables (Qenani, MacDougall, \& Sexton, 2014). The students surveyed were Engineering and Agriculture, Food and Environmental Science students at a single university in the USA $(n=978)$. The most influential factor on students' self-confidence in employability was participation in a placement (internship) experience 
during their academic studies. Students who had participated in a placement were 2.5 times more likely to be confident in their employability than those who had not (controlling for other factors). Other factors that contributed to confidence included self-management of career behaviours (those that proactively aligned their academic experience with career goals through choosing particular courses, consulting with faculty, attending career fairs, etc.) and college reputation. Academic factors, such as grade point average, class standing and choice of major had some influence on confidence, but less than the factors already mentioned. There was also some positive correlation between self-reported employability and reported skills preparation (critical thinking, communication and discipline-specific skills) and personal characteristics (outgoing or trustworthy).

Finally, in a third study from Australia, surveys were used to investigate students' self-reported use of twelve strategies linked to improved employability (Kinash, Crane, Judd, \& Knight, 2016). Similar surveys were sent to graduates, employers and higher education personnel. Students $(n=442)$ and graduates $(n=102)$ were asked to report on the strategies that they were or had used, whereas employers $(n=53)$ were asked to report on the strategies that their organisation valued in the recruitment of graduates, and higher education personnel ( $\mathrm{n}$ $=108$ ) were asked to report on the strategies that they provided. The strategy most often selected by students (74\%), graduates $(74 \%)$ and employers (87\%) was: work experience, internships and placements, whereas these were only provided by 40 percent of higher education personnel. Other strategies selected by more than 40 percent of students were career advice (59\%), part-time work (53\%), networking (49\%), extracurricular activities (48\%), and volunteering (47\%). Where students choose to invest time and effort speaks to value, although all of that value is not necessarily attributable to employability. For example, students engage in part-time work to earn money, not just to improve their employability. The opportunities that students have to participate in different activities is also variable and will of course influence use. However, for so many students to engage in work experience, placements or internships, speaks strongly to the value that students place on these experiences, especially given that only 40 percent of higher education personnel reported providing these opportunities.

These three studies, spanning three international contexts, suggest that students have variable understanding of what promotes employability, but agree that placements are an important opportunity. However, all of these investigations have focussed on students' perceptions of specified strategies, or opportunities and support provided by universities. Here we build on that understanding by taking a broader approach to investigating what science students do to make themselves employable and to differentiate themselves from other graduates, with focus on the following research questions:

1. Do students prioritise gaining employment or long-term employability for future careers and performing well in the workplace?

2. What do students believe will help them gain employment or develop employability?

This research was conducted through secondary analysis of interviews primarily investigating science students' perceptions and experience of work-integrated learning at four Australian universities. While much of that discussed pertained to students' experience of the curriculum, students were first asked more broad questions about their career intentions, confidence and behaviours related to employability, and it is from those responses that we are able to extract a broader understanding of students' conceptions of employability and factors that will differentiate them in the graduate employment market. We necessarily describe both the primary data collection and subsequent data analysis.

\section{Primary research and student demographic}

As part of a national project, funded by the Australian Office for Learning and Teaching, with support from the Australian Council of Deans of Science (Johnson et al., in press), semi- 
structured focus groups and individual interviews were used to investigate science students' perceptions and experience of work-integrated learning at four Australian universities. The objective of that project was to investigate student engagement with work-integrated learning in science, with emphasis on factors that encourage or discourage science students from participating in, and making meaning from, work-integrated learning.

In total, 138 undergraduate students participated across 27 focus groups and nine individual interviews. All second- and third-year science students at the four universities were invited to register their interest in participating through direct emails and promotion of the opportunity by teaching staff in core science units. A registration survey was used to collect demographic information and to identify participants' employment status, intent to seek new opportunities and interest and confidence related to employment. 187 eligible students registered their interest and participants were selected to maximise the representation of students enrolled in difference science disciplines at each university. Of those who participated, 80 students were enrolled in a Bachelor of Science, 12 were enrolled in an advanced (four-year) Bachelor of Science, 17 were enrolled in a double degree combining a Bachelor of Science with another course (including engineering, psychology, commerce, education, journalism, and international studies) and the remaining 29 students were enrolled in more discipline-specific science courses (including biomedical science, environmental science and forensic science). Participants ranged in age from 18 to 43, with a median age of 21 . Two-thirds of the participants indicated that they were female, 88 percent were domestic students and 91 percent were enrolled in full-time study. None were employed full-time, but 55 percent were employed casually $(43 \%)$ or part-time (12\%), and only 41 percent were unemployed.

Semi-structured focus groups were used because group interaction encourages elaboration of concepts and allows analysis of what participants know, as well as how they understand and conceptualise the issue under discussion (Wibeck, Dahlgren, \& Öberg, 2007). These data were supplemented with individual interviews to enable participation where students could not attend a scheduled group. Both focus group and individual interviews allowed for in-depth exploration of students' perceptions and experiences.

Students' understanding of the term 'work-integrated learning' was explored before a definition and examples of work-integrated learning (WIL) were provided to ensure consistent framing of subsequent questions. WIL was defined to participants as 'learning activities that incorporate work, employment and careers and help students develop the capabilities required for the workplace'. Examples included experiences situated in a workplace, such as internships or placements, as well as other experiences that are authentic to the workplace but happen on campus, such as case studies, simulations, complex laboratory classes or other authentic workplace tasks.

This research was carried out in accordance with the National Statement on Ethical Conduct in Human Research and was approved by the Deakin Faculty of Arts \& Education Human Ethics Advisory Group (HAE-17-013).

\section{Secondary analysis}

In order to specifically investigate students' understanding and priorities related to employment and employability, relevant data was first extracted from the larger data set. The data analysed included student responses to the following questions:

1. What would you like to do with your science degree and how confident are you that you will get that opportunity?

2. What do you do to try and make yourself more employable, and how would you differentiate yourself from other science graduates?

All other excerpts of dialogue in which students referred to their beliefs, behaviours or intentions related to employment and employability were also included in the analysis. This 
included any discussion about obtaining employment, workplace performance, capabilities or experiences linked to each of these, and the steps that students had taken or intended to take to gain opportunities, improve themselves or differentiate themselves from others. Data was then subject to qualitative analysis to identify recurring themes (Miles, Huberman, \& Saldana, 2014).

\section{Findings}

Students were more focused on employment than on employability. They had a nuanced understanding of what promotes employment, however, their conceptions varied and were likely influenced by both their experience and their aspirations. Below we share key findings emerging from the survey and interviews.

\section{Survey results}

Responses to the registration survey confirmed perceptions that were prominent in interviews. Almost all students (96\%) reported that they thought about their employment prospects often. Most students (81\%) intended to seek new employment at graduation, while 15 percent were not sure and one student indicated that they did not intend to seek new employment (four did not respond). However, only 59 percent indicated that they knew what job or career they would seek after graduation (Figure 1). The majority of students (76\%) were unsure whether they would get their preferred job at graduation and 53 percent were not confident that they would get a job at all. Despite this, 62 percent were confident that they would be able to differentiate themselves from other graduates and 79 percent were confident in their ability to succeed in their workplace of choice.

I think about my employment prospects often

I know what job or career I will seek after I graduate

I am confident that I will get a job after graduation

I am confident that I will get the job I want after graduation

I am confident that I have the ability to succeed in my workplace of choice

I am confident that I will be able to differentiate myself from other graduates

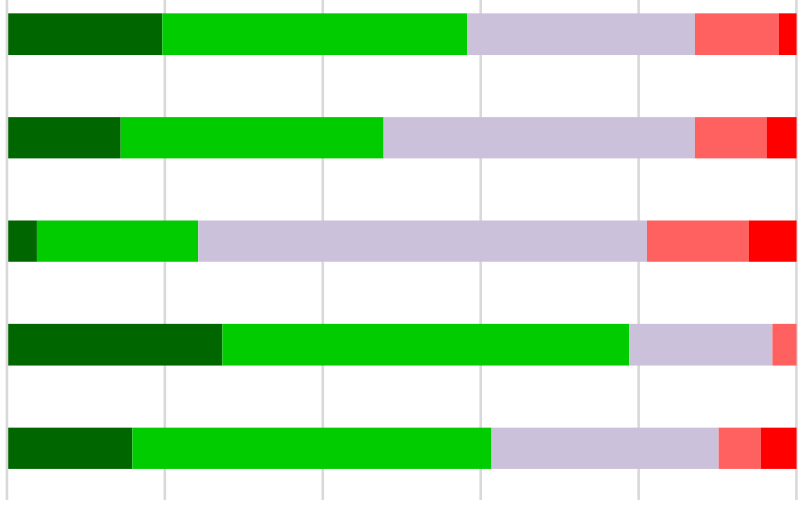

0

$20 \quad 40$

60

80

-Strongly agree $\square$ Agree $\square$ Unsure $\square$ Disagree $\square$ Strongly disagree

Figure 1: Student agreement (\%) with statements about employment prospects and planning.

\section{Interview findings}

\section{Students were more focused on employment than employability}

Students were most concerned about immediate employment and focussed on things that would improve their chances of gaining a job. They frequently expressed concerns about competition for jobs and the limited availability of positions in their field. Many were not confident about obtaining employment after graduation and this was exacerbated where they were uncertain about the jobs or careers that their degree would qualify them to pursue. Some 
students were concerned about gaining a specific job or career. Others were primarily concerned with gaining full-time employment and were prepared to compromise on the type of job, often out of necessity:

I'm at that point where I don't care if it's a chem[istry] lab, I need a job that's full-time.

For other students, there was less urgency because they perceived themselves as having plenty of time before they graduated or needed to join the workforce. Others dismissed concerns because they had wide career interests:

I'm really interested in conservation work, so anything from park ranger to conservation research would make me happy. I think because I've got such a wide range of what I want to do, l'll get there eventually. There's a lot of options in there.

Students were most focused on gaining employment, but some also emphasised the importance of being able to perform well in the workplace. These students wanted to be able to "hit the ground running" and were interested in understanding the types of tasks they would encounter so that they could develop competencies in those areas and demonstrate their value to colleagues or organisations.

2. Student perceptions of factors that promote employment were nuanced, but varied with the experience and aspirations of the individual

Most students agreed that their degree alone was not sufficient assurance for gaining a job or career. However, the factors that they thought would make a difference were variable, as were their motivations and degree of engagement in behaviours that they believed would enhance their degree. Students spoke about numerous ways in which they had, could or should enhance their employability, but most students perceived gaining work experience and developing networks as most important. Where students referred to factors that might help them to develop or gain opportunities, it was often not clear whether students were talking about employment or employability or conflating these closely related concepts, so we have not attempted to differentiate between these in our analysis. There was also overlap between the factors described. For example, students valued work experience itself, as well as its impact on gaining skills and networks.

a) Work experience (including that gained through employment or placements)

The importance of work experience was raised in every interview (group or individual). Here we cluster work experience gained through placements, employment, or volunteering, because work experience was often discussed by students in general terms and was inclusive of experience gained through all of these. However, when we provided students with a definition and examples of work-integrated learning and asked students what was most valuable, most students chose placements above on-campus learning opportunities, because they perceived these to be an opportunity to gain work experience.

Students valued work experience because they saw it as something that was desired or required by employers. They also saw it as an opportunity to gain important networks, to develop personally and professionally, and to gain evidence of what they were capable of. As indicate din the following comment:

I think they want someone to show that they've done that in the past and they can prove that, they want people to show that they're able to do the job. So I think the way that you can improve your employability is by having real world experience and examples in the past you can point to show that you are able to do this job.

In terms of their own development, students spoke about work experience being an opportunity to develop important skills and understanding: including both discipline-specific and transferable skills; understanding of their discipline, workplaces and roles in industry; and professional expectations. 
Students were most interested in work experience related to their discipline or career interests. Students that had gained relevant work experience tended to be more confident about their career prospects than students that had not and linked their confidence to those experiences:

I've worked full time for the last two years in conservation, I have a really good network. I've met a lot of people in councils and things so I'm very confident that if I go for any grad positions or possibly even council positions because I know people there, I've worked in the industry, that that's what will get me the work. I see my degree as a requirement but it's not the thing that gets me the job, it's my actual work experience.

Conversely, students that lacked work experience often discussed this in relation to their lack of confidence:

...it's that fear of going into a job and going, I have no clue what I'm doing and basically failing. Just rocking up and them going, 'Can you do this for us?' and you're going, 'I have no clue what I'm going to do', like not knowing where to start.

Students were less certain about whether unrelated work experience gained through part-time or casual jobs, previous careers or placements had value. Some students appreciated this experience as an opportunity to develop transferable skills and professional understanding, especially where they had broad career interests. However, others questioned the value of unrelated work experience:

...going for a science job is quite different in comparison to going to a facilities management job. I'm actually getting anxious just thinking about it, to be quite honest.

Some students were adamant that placements needed to be closely tied to their career interests to be worthwhile, especially where they were already having difficulty juggling study with paid employment or other commitments, where they were most interested in using the work experience opportunity to develop discipline-specific technical skills and networks, or where they had extensive professional experience. Others were more open to broad placement experiences.

b) Networks

The perceived value of networks was also very prominent. Students commonly believed that knowing people within an industry would be important to finding and gaining employment, and would help them to develop a reputation and relationships within industries. Students frequently spoke about work-integrated learning or extra-curricular activities related to their study, being valuable opportunities to build a network of professionals who might hire or recommend them. Some stressed that networks were even more important than capabilities or knowledge:

I don't think it's based now on what you know, but I think it's about who you know. So networking is a huge thing that you got to do, but I think also getting yourselves in internships so you get to know employers and employers get to know you so they have a face to the name... I think that also helps [with] employability.

Some students emphasised the importance of placements and other experiences for providing the opportunity to showcase capabilities or personal attributes that might lead to additional opportunities:

If you do the work placement and you're known by a company to not be a bumbling idiot then you tend to do better in general, because one company talks to another company and that one talks to the next one. 
Students that were not confident about their employment prospects sometimes spoke about concerns over having no professional networks in their industry of choice, whereas others were confident because of their networks:

I really appreciate the networks that I [have] built as well as the mentorship that's available - in terms of an industry expert helping you along the way in the project that you're doing, specific to the work that you're doing, in whatever company it is - but also in your progression through your degree and past that, how would you get past all the obstacles that come your way. And, having a mentor who has gone through that, or has had a similar experience, and their advice makes it a lot easier and less threatening.

\section{c) Extra-curricular activities}

Students perceived extracurricular activities as beneficial for developing skills and knowledge, developing their networks and reputation, as experience or achievements that they could list on their resumes, and for demonstrating and developing their interest in the field. While some extra-curricular opportunities were valued because they provided work experience, students spoke about a wide variety of other activities, including attending industry events, participating in industry associations and committees, attending networking events, involvement in student clubs and committees, and tutoring. Students reported that they participated in these kinds of activities to make their "resume look good", in the hope that it would help to distinguish them from other graduates:

I have a lot of pastoral care mentoring roles - and organisational, event management sort of things - that I am part of. I think that develops quite a different set of skills to what a science degree does. The analytical thinking and the problem solving of science is fantastic, but it's very different from some of the communication and organisational skills you develop [from mentoring or as a research assistant]. I think that those things that I'm involved in, as well as being part of social clubs and societies, is hopefully going to get me a little bit ahead of the crowd.

d) Transferable vs. discipline-specific or technical skills

Students' perceptions regarding skills, and in particular the types of skills that are important to employers, were variable and sometimes at conflict. Some students thought that technical or discipline-specific skills would be most important to gaining employment and transitioning into the workplace, whereas others thought that transferable skills would be more important and emphasised the importance of these for success across different roles, workplaces and industries. Many students emphasised both and some were unsure. Students spoke about the importance of skills for gaining jobs, transitioning into and performing well in the workplace.

Many students were concerned that they had been given insufficient opportunity to develop necessary discipline-specific or technical skills within their degree structure. These students suggested that their studies provided a foundational, broad knowledge and basic skills, but lacked appropriate training in discipline-specific technical skills that would enable them to 'step into' a workplace role:

.... lot of degrees nowadays have become much more holistic which is great but, at the same time, it does mean that a lot of information and a lot of technical expertise is lost as a result, the more intricacies of particular disciplines get removed. For a vocational science such as geology where it is important to have these technical skills and expertise in order to be in a position of consulting or expertise, technical expertise, it is a big detriment to students nowadays.

In contrast, other students were concerned that their degree was overly technical and would not prepare them for alternative career options: 
My line of study is a little bit more specific, I'm studying atmospheric science, so there isn't a lot of employ[ment] options when you leave uni[versity]. There's really one main place where you can go, so it is a little bit worrying, because there's going to be a lot of competition and if you don't get in it's like, what do you do?

Students also discussed the importance of being able to effectively evidence their skills:

... a lot of the lab[oratory] work has been very helpful and it allows me to put down the skills on my resume saying that l'm proficient in this, this and this and l've had so many hours working in the lab

Some students discussed this as a difficulty and expressed concern over their ability to provide meaningful examples to employers. One of the reasons why students valued work experience (including placements) so much was because they saw it as an opportunity to evidence their skills in ways that would be valued by employers. Students spoke about other learning or assessment in their course, that had helped them to develop or reflect on their skills, but they rarely discussed these in relation to evidencing their skills to employers. Some students specifically questioned whether employers would value experience gained in a university context as much as that gained in the workplace, although some acknowledged that projects or work completed for an industry partner would be more valuable evidence of their experience and capabilities.

\section{Choice of degree, subjects or specialisation}

A small proportion of students spoke about their choice of degree, subjects or specialisation being relevant to employment. Some of these students thought that the mix of study areas they had chosen would be beneficial to gaining a diverse range of experiences, skills and understanding. These students spoke about roles requiring expertise across multiple disciplines, the importance of being able to work with people from other industries, and diverse experiences that they thought would broaden the types of positions that they could apply for:

I've got other degrees and other skills and other workplace skills to bring so you just have to be really broad I guess. You can't just be one anymore, not anymore. You used to be able to just specialise but now you have to be able to have other skills as well.

Others suggested that having completed units in subjects that few other graduates in their discipline were likely to have studied would set them apart. Likewise some students were completing a double degree and thought that this would help to differentiate them from other science graduates.

\section{a) Further education}

Some students felt it was 'necessary to have a postgraduate degree' to find relevant employment. Several students intended to pursue further education to specialise, further develop knowledge and skills or make themselves more employable:

I probably want to get into a food science industry. I've had a look at graduate jobs at the moment but it seems like I need to do some sort of postgrad stuff to get in the industry.

While some students perceived further study to be a requirement for future employment, either as the next logical step in their pathway to getting a specific job, or as a likely necessary step for further career progression, others considered it a fall-back option if they were unable to secure a job once graduated:

[I'm trying to] keep up my grades to keep honours and Masters open as an option at the end of my degree. If that's what the job market is looking for, people with honours, then I'll pursue that. 


\section{b) Academic achievement}

With the exception of students who required particular grades for further study, grades were not perceived as being particularly influential. Most students agreed that experience balanced or outweighed grades, as long as the grades obtained were sufficient to pass. Some had even made a conscious decision to pursue other experiences at the expense of study time and grades:

They're focussed on grades not [practical experience] - whereas l've let a few grades slip so that I can get in ... some practical experience.

c) Personal characteristics

The impact of personal characteristics on employment was only occasionally discussed. However, several international students raised concerns about domestic students being preferred:

[I'm] not that confident to be honest, not because of my abilities, but just because of the position I'm in because I'm not a citizen, so that kind of... means a little bit of a disadvantage because most graduate programs hire citizens. So it's a bit of work to go through which organisations and companies will accept you and which won't.

Students also referred to personality traits such as persistence, determination, passion, common-sense and work ethic in relation to their belief that they would (eventually) gain employment.

\section{Discussion}

The students in this study recognised that having a degree is not sufficient to guarantee graduate employment. Consequently, most students had, or were keen to participate in, opportunities that would allow them to 'value add' to their degree. These perceptions are not unique to Australian or science students; they closely reflect those reported for students from other disciplines and international contexts (Glover, Sue, \& Youngman, 2002; Tomlinson, 2008; Tymon, 2013). Students also recognised that employability is complex and influenced by many factors. However, their understanding of those factors and their relative importance was variable, as was their understanding of the career pathways that they might pursue. This reflects a concerning gap in the curriculum, because graduates need to evidence and articulate their own employability to gain opportunities (Oliver, 2015); and being able to identify opportunities, and represent skills in a way that is relevant to employers and roles, is vital to career management (Bridgstock, 2009). Several studies have highlighted the importance of student-focussed communication and assessment to ensure that students actually recognise the skills that they are developing (Hill et al., 2018; Jorre de St Jorre \& Oliver, 2018). In addition to that, the analysis of the findings of this study highlights the importance of explicitly designing curriculum to help students to understand the career opportunities that they might pursue relative to their specific degree; the skills and abilities that are needed for these; and the experiences through which they might develop and evidence these. Furthermore, to engage students, we need to help them to address their greatest and most immediate concerns about gaining employment at graduation, while also setting them up for successful and fulfilling careers in the longer term.

The largest area of inconsistency was in students' conceptions of the relative importance of transferable and discipline-specific skills. Many students perceived both skill sets as important, however, some seemed overly concerned with discipline-specific, and especially technical skills such as laboratory techniques and practices. This likely reflects a lack of appreciation for the importance of transferable skills to science-trained professionals (Harris, 2012) and employers of Science, Technology, Engineering and Mathematics (STEM) graduates (Coll \& Zegwaard, 2006; Deloitte, 2014; Sarkar et al., 2016). With the fast rate of change in STEMrelated industries, many of the technical skills learned at university become obsolete, or are 
less important than the ability to learn and adapt to change (Deloitte, 2014; Innovation and Science Australia, 2016). Furthermore, science graduates attain diverse careers beyond science, research and technology, and in many of these, technical skills are not important at all (Harris, 2012; Palmer, Campbell, Johnson, \& West, 2017). That is not to say that disciplinespecific skills and understanding are not important, especially for students seeking technical positions. However, employers are clear that it is broader transferable skills that will distinguish preferred applicants (AlphaBeta, 2016; Sarkar et al., 2016).

Some students were very proactive about seeking opportunities (in or beyond their degree) to add value or fill perceived gaps in their skills development, networks or experience. However, students' understanding of the opportunities that would be most valuable, and that were available, were variable. In fact, students who participated in the focus groups often learned about new opportunities by comparing experiences with other students. Students did agree that relevant work experience and networks are of most use to gaining employment. Students' perceptions of the advantages of work experience, in particular placements, is consistent with other studies (Kinash et al., 2016; Qenani et al., 2014; Sarkar et al., 2016; Tymon, 2013). However, because of the broader framing of our questions, students in our study often spoke about work experience in general terms, and were conscious of and interested in gaining experience not only through placements, but also through paid employment or volunteering.

Students' perception of the importance of networks seems to be more prominent in our study than in the previous studies, although Kinash et al. (2016) did report that 49 percent of students used networking as a strategy. This is likely because students in our study were invited to talk about their personal actions. They appreciated opportunities provided by their university to expand their networks, such as industry events and placements, but they also discussed strengths and weaknesses in their own personal or professional networks and ways in which they had sought to add to these beyond opportunities provided by their institution.

Student perceptions about the importance of work experience and networks are consistent with employer and educator perspectives (Bridgstock, 2016). Employers report that providing work-integrated learning opportunities, in particular placements and projects, is a key recruitment strategy as it provides access to a pool of talent that they can screen for employment (Atkinson et al., 2015; AWPA, 2014; PhillipsKPA, 2014); but they also viewed provision of industry experiences to students as a way to contribute to their industry's future (Atkinson et al., 2015). Further, employers often think that placements help students become better prepared for the workplace (Coll et al., 2009). The opportunity to demonstrate their capabilities and build their professional network prior to graduation, rather than needing to build this from scratch upon graduation, is highly beneficial for students (Bridgstock, 2016). These factors likely explain, at least in part, why students who have participated in WIL activities tend to gain employment more quickly after graduation than students without WIL experience (Ferns et al., 2014).

Students were most interested in pursuing work experience and networks that they perceived as relevant to gaining a job. However, some students were not sure what jobs or careers they could actually pursue, and it is likely that many students were not aware of the breadth of careers that science professionals experience. It is likely that many students overlook opportunities that would help them to gain experience and networks, as well as skills and understanding that are relevant to them (and to employers). Active intervention to help students appreciate the diversity of careers available and the range of relevant skills and experience, would help to address student concerns about employment opportunities, and provide them with more options for gaining helpful experience during study. This is highly relevant to students in science, who have poorer full-time employment outcomes immediately following graduation than their peers in more vocational disciplines (QILT, 2018).

Interestingly, some students in other studies afforded considerable importance to grades, with some students seeing these as instrumental to positioning themselves above their competitors in the graduate labour market (Qenani et al., 2014; Tomlinson, 2008; Tymon, 2013). In 
contrast, grades and assessment were rarely discussed by students who participated in our study, and students even spoke about prioritising activities that would help them to gain experience or networks, despite likely negative impacts on their academic achievement.

\section{Conclusion}

This study has shown that students appreciate the importance of gaining experience and skills beyond those provided by the formal curriculum. Students did not isolate experiences in the taught curriculum from other experiences that develop employability. They also grasped the importance of industry relevance and looked for opportunities to develop and highlight their capabilities in what they perceived as a very competitive employment market. However, students' understanding of the relative importance of experiences and skills that would enhance their employability was variable, as was their understanding of the career pathways that they might pursue. Thus our analysis highlights the importance of explicitly designing curriculum to help students understand: the career opportunities available; the skills and abilities needed for diverse careers; and the experiences through which they might develop and evidence these. Furthermore, students were most concerned with initial employment at graduation, and are likely to be more engaged if we help them to address these immediate concerns while also developing their appreciation for longer-term career development needs. 


\section{References}

ACEN. (2015). Universities and industry groups collaborate to develop a national work integrated learning strategy [Press release]. Retrieved from http://cdn1.acen.edu.au/wpcontent/uploads/2015/03/WIL-media-release-11Mar2015.pdf

AlphaBeta. (2016). The new basics: Big data reveals the skills young people need for the New Work Order. Australia: The Foundation for Young Australians.

Atkinson, G., Misko, J., \& Stanwick, J. (2015). Work integrated learning in STEM disciplines: employer perspectives. National Centre for Vocational Education Research. http://www.chiefscientist. gov. au/wp-content/uploads/NCVER_WIL-employer-perspectives.pdf

Australian Association of Graduate Employers. (2018). 2018 AAGE Employer Survey.

AWPA. (2014). Work Integrated Learning AWPA Scoping Paper. Canberra: Australian Workforce and Productivity Agency.

Bridgstock, R. (2009). The graduate attributes we've overlooked: Enhancing graduate employability through career management skills. Higher Education Research \& Development, 28(1), 31-44. doi: 10.1080/07294360802444347

Bridgstock, R. (2016). Graduate employability 2.0: Social networks for learning, career development and innovation in the digital age. Retrieved from file:///C:/Users/Study/AppData/Local/Temp/Graduate-employability-2-0-discussion-paper-1.pdf

Coll, R. K., \& Zegwaard, K. E. (2006). Perceptions of desirable graduate competencies for science and technology new graduates. Research in Science \& Technological Education, 24(1), 29-58. doi: 10.1080/02635140500485340

Curtis, D., \& McKenzie, P. (2001). Employability skills for Australian industry: Literature review and framework development. Melbourne: Australian Council for Educational Research.

Deloitte. (2014). Australia's STEM workforce: A survey of employers. Australia: Office of the Chief Scientist.

Ferns, S., Campbell, M., \& Zegwaard, K. (2014). Work Integrated Learning. In S. Ferns (Ed.), Work Integrated Learning in the Curriculum (pp.1-6). NSW: Higher Education Research and Development Society of Australasia.

Glover, D., Sue, L., \& Youngman, A. (2002). Graduateness and employability: Student perceptions of the personal outcomes of university education. Research in Post-Compulsory Education, 7(3), 293-306. doi: 10.1080/13596740200200132

Harris, K.-L. (2012). A background in science: What science means for Australian society. Australia: Centre for the Study of Higher Education, University of Melbourne and the Australian Council of Deans of Science.

Hill, M. A., Overton, T. L., Thompson, C. D., Kitson, R. R. A., \& Coppo, P. (2018). Undergraduate recognition of curriculum-related skill development and the skills employers are seeking. Chemistry Education Research and Practice. doi: 10.1039/C8RP00105G

Innovation and Science Australia. (2016). Performance Review of the Australian Innovation, Science and Research System. Canberra: Australian Government Office of Innovation and Science Australia.

Jackson, D. (2014). Testing a model of undergraduate competence in employability skills and its implications for stakeholders. Journal of Education and Work, 27(2), 220-242. doi: $10.1080 / 13639080.2012 .718750$

Jackson, D. (2015). Employability skill development in work-integrated learning: Barriers and best practice. Studies in Higher Education, 40(2), 350-367. doi: 10.1080/03075079.2013.842221

Johnson, E., Rice, J., Varsavsky, C., Holdsworth, J., Ward, J., Skelly, D., Campbell, M., Jorre de St Jorre, T., Elliott, J., \& Aughterson, J. (in press). Successful WIL in science. Canberra: Department of Education and Training, Commonwealth of Australia.

Johnson, E. \& Rice, J. (2016). WIL in science: Leadership for WIL. Canberra: Office of the Chief Scientist.

Jorre de St Jorre, T., \& Oliver, B. (2018). Want students to engage? Contextualise graduate learning outcomes and assess for employability. Higher Education Research \& Development, 37(1), 44-57. doi: 10.1080/07294360.2017.1339183 
Kavanagh, M. H., \& Drennan, L. (2008). What skills and attributes does an accounting graduate need? Evidence from student perceptions and employer expectations. Accounting \& Finance, 48(2), 279-300. doi: doi:10.1111/j.1467-629X.2007.00245.x

Kinash, S., Crane, L., Judd, M-M., \& Knight, C. (2016). Discrepant stakeholder perspectives on graduate employability strategies. Higher Education Research \& Development, 35(5), 951967. doi: $10.1080 / 07294360.2016 .1139555$

Miles, M. B., Huberman, A. M., \& Saldana, J. (2014). Qualitative data analysis. London, UK: Sage Publications.

Oliver, B. (2015). Redefining graduate employability and work-integrated learning: Proposals for effective higher education in disrupted economies. Journal of Teaching and Learning for Graduate Employability, 6(1), 56-65.

Oliver, B., \& Jorre de St Jorre, T. (2018). Graduate attributes for 2020 and beyond: Recommendations for Australian higher education providers. Higher Education Research \& Development, 37(4), 821-836. doi: 10.1080/07294360.2018.1446415

Orrell, J. (2011). Good practice report: Work-integrated learning. Sydney: ALTC.

Palmer, S., Campbell, M., Johnson, E., \& West, J. (2017). Occupational outcomes for Bachelor of Science graduates in Australia and implications for undergraduate science curricula. Research in Science Education, 48(5), 989-1006. doi: 10.1007/s11165-016-9595-x

Patrick, C., Peach, D., Pocknee, C., Webb, F., Fletcher, M., \& Pretto, G. (2009). The WIL report: A national scoping study. Final Report to the Australian Council for Teaching and Learning, ACEN. Sydney, Australia: Australian Council for Teaching and Learning.

PhillipsKPA. (2014). Engaging employers in work integrated learning: Current state and future priorities. Richmond, Melbourne: PhillipsKPA.

Qenani, E., MacDougall, N., \& Sexton, C. (2014). An empirical study of self-perceived employability: Improving the prospects for student employment success in an uncertain environment. Active Learning in Higher Education, 15(3), 199-213. doi: $10.1177 / 1469787414544875$

QILT. (2018). 2017 Graduate Outcome Survey. Canberra, Australia: Australian Government Department of Education and Training.

Sachs, J., \& Rowe, A. (2016). 2016 Good Practice Report: Work Integrated Learning (WIL). Canberra: Department of Education and Training.

Sakar, M., Overtona, T., Thompson, C., \& Rayner, G. (2016). Graduate employability: Views of recent science graduates and employers. International Journal of Innovation in Science and Mathematics Education, 24(3), 31-48.

Sarkar, M., Overton, T., Thompson, C., \& Rayner, G. (2016). Graduate employability: Views of recent science graduates and employers. International Journal of Innovation in Science and Mathematics Education, 24(3), 31-48.

The Australian Industry Group. (2018). Skilling: A national imperative. Retrieved from file://CC:/Users/Study/AppData/Local/Temp/Survey_Report_WFDNeeds_Skilling_Sept2018.pdf

Tomlinson, M. (2008). The degree is not enough: Students' perceptions of the role of higher education credentials for graduate work and employability. British Journal of Sociology of Education, 29(1), 49-61. doi: 10.1080/01425690701737457

Tomlinson, M. (2012). Graduate employability: A review of conceptual and empirical themes. High Educ Policy, 25(4), 407-431.

Tymon, A. (2013). The student perspective on employability. Studies in Higher Education, 38(6), 841-856.

Wibeck, V., Dahlgren, M. A., \& Öberg, G. (2007). Learning in focus groups: An analytical dimension for enhancing focus group research. Qualitative Research, 7(2), 249-267. doi:10.1177/1468794107076023

World Economic Forum. (2016). The future of jobs: Employment, skills and workforce. Geneva, Switzerland: Strategy for the Fourth Industrial Revolution.

Yorke, M. (2006). Employability in higher education: What it is - what it is not. Learning and Employability, Series 1. UK: Higher Education Academy. 